\section{Cativeiro e \\ compadrio em \\ um porto atlântico \\ (Rio Grande, 1780-1850)}

\author{
Marcelo Santos Matheus [*] \\ [*] Professor de História do Instituto Federal \\ do Rio Grande do Sul (IFRS). Canoas (RS), Brasil. \\ marcelo.matheus@canoas.ifrs.edu.br
}

ORCID: http://orcid.org/ 0000-0002-9313-4678

\begin{abstract}
Resumo: Dentro dos ditames de uma sociedade católica e escravista, o compadrio foi uma das formas de associação que os africanos e seus descendentes encontraram para (re)signifcar suas vidas e tornar menos dolorosa a experiência do cativeiro. Nesse sentido, este artigo tem por objetivo o estudo dos laços de compadrio a partir do batismo de escravos, com foco na documentação produzida em Rio Grande, porto ao sul do Brasil que mantinha relações econômicas e sociais com diversas partes do Atlântico, entre 1780 e 1850. Foi possível observar que a busca pelo batismo não respondia apenas à norma eclesiástica. Da mesma forma, identificamos mudanças no padrão do compadrio ao longo do tempo, com algumas diferenças interessantes entre a tendência geral e o compadrio de africanos em particular. Por fim, o compadrio, além de produzir relações sociais diversas, podia potencializar as chances de obtenção da liberdade.
\end{abstract}

Palavras-chave: Escravidão; Compadrio; Sul do Brasil.

\section{Slavery and godparenthood in an Atlantic port city (Rio Grande, 1780-1850)}

\begin{abstract}
Within the norms of a Catholic slave society, the compadrio (godparenthood) was one of the forms of association that Africans and their descendants found to (re)signify their lives and make the experience of captivity less excruciating. In this article, I study the bonds of compadrio - registered during the baptismal cerimonies of slaves between 1780 and 1850 -, focusing on the documentation produced in Rio Grande, a port city in southern Brazil that maintained economic and social relations with various parts of the Atlantic. In my analysis, I found that the search for baptism did not respond only to the ecclesiastical norm. Likewise, I was able to identify changes in the pattern of compadrio over time, with some remarkable differences between the general trend (from free, freed, and enslaved Brazilians) and the compadrio established by Africans in particular. Finally, I show that compadrio, in addition to diversify social relationships, was a way that enslaved Africans used to enhance their chances of obtaining freedom.
\end{abstract}

Keywords: Slavery; Compadrio; South of Brazil. 


\section{Introdução}

Este estudo tem por objetivo investigar como os escravos utilizaram, dentro dos limites impostos por aquela realidade (i.e., pela sociedade escravista brasileira de então), o parentesco fictício como forma de associação e, logo, de sobrevivência e para melhorar suas condições de vida. Para tanto, o lócus da pesquisa é a localidade portuária de Rio Grande, no sul da América portuguesa e, depois, do Império brasileiro. Por óbvio, as principais fontes exploradas são os registros de batismo produzidos na localidade, entre c.1780 e 1850.

Rio Grande (ou Forte Jesus, Maria, José) foi um dos primeiros núcleos populacionais organizado por súditos do rei português onde hoje é o Rio Grande do Sul (doravante RS). Fundada em 1737, foi elevada à categoria de vila em 1751. Em um contexto bélico entre os Impérios português e espanhol, com repercussões não só na Europa, como também nos seus domínios, em 1763 a localidade foi invadida e ocupada pelos espanhóis. Contudo, em 1776 os luso-brasileiros expulsaram os invasores e retomaram definitivamente a vila (Kühn, 2004).

A partir desse momento, cresceu a concessão de sesmarias no extremo sul da América portuguesa, aumentando a migração de luso-brasileiros para o RS e, por consequência, a invasão das terras dos índios guaranis, especialmente na região oeste da capitania (chamada de Campanha sul-rio-grandense), onde os guaranis criavam milhares de cabeças de gado, processo que se intensificou em 1801, quando os Sete Povos das Missões, na margem oriental do rio Uruguai, foram definitivamente integrados ao império português (Osório, 1990, 2007; Farinatti, 2010; Aladrén, 2012). A apropriação dessas riquezas (terras e animais) e o estabelecimento de estâncias, na Campanha, e das charqueadas, principalmente em Pelotas - freguesia pertencente a Rio Grande até os anos 1830 - a partir da década de 1780, fez com que essa última crescesse vertiginosamente (Scherer, 2008). E uma das razões para isso foi o fato da vila ser uma localidade portuária, voltada para o Atlântico, sendo até hoje o principal porto do RS.

Nesse contexto, ou seja, depois que a carne de gado passou a ser manufaturada antes de ser exportada, era pelo porto de Rio Grande que saíam os produtos vendidos pelo RS, como o trigo, mas principalmente os artigos envolvidos na produção pecuária e seus derivados (charque, couros etc.) que tinham como destino as plantations brasileiras, e também Cuba, EUA, Europa, entre outros, e entrava a maior parte das mercadorias compradas pelos sul-rio-grandenses (Berute, 2006; Vargas, 2016; Gomes, 2018). Com efeito, uma dessas "mercadorias" eram os escravos, tanto africanos como crioulos.

Entre 1780 e 1850, nada menos do que 5.074 escravos foram batizados na igreja de Rio Grande. Contudo, como é possível observar no mapa abaixo, durante muito tempo Rio Grande abarcou um vasto território, a maior parte dele rural e de onde, dentro do nosso recorte temporal, diversas vilas (Pelotas, Canguçu, Piratini etc.) se emanciparam. 
Em razão da especificidade da produção da fonte, os párocos anotavam onde (se na Matriz de Rio Grande, em alguma fazenda ou oratório privado) o batismo havia sido celebrado. Assim, daqueles 5.074 registros, analisamos somente 3.710 batismos, ou apenas aqueles celebrados de fato na igreja de Rio Grande - o que, se não garante que sejam somente os batismos de escravos que (con)viviam e produziam relações diversas na vila, ao menos fornece ao pesquisador um pouco mais de controle sobre a população foco e objeto do estudo.

Mapa - em destaque os limites do município de Rio Grande, em 1809

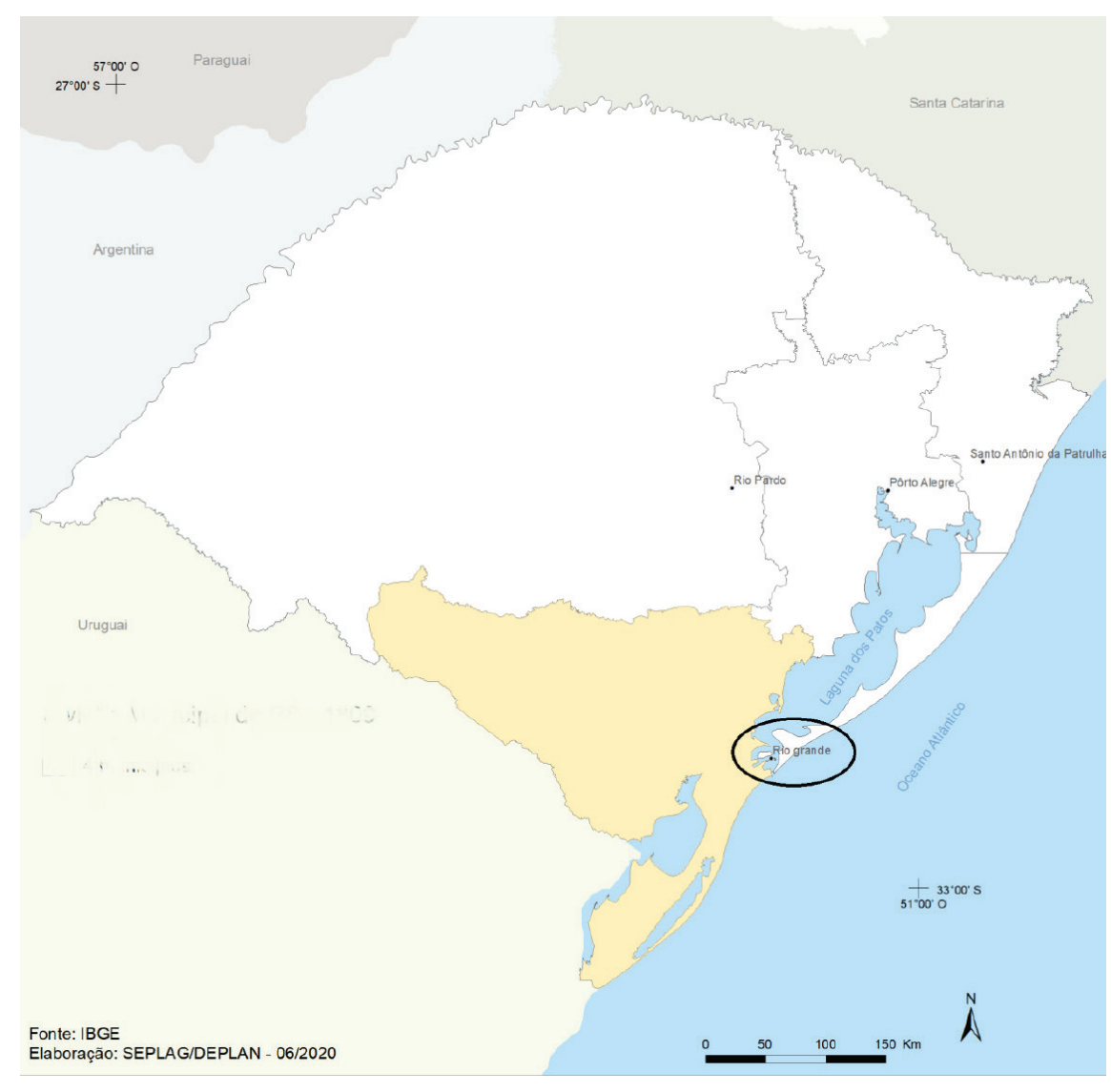

Fonte: adaptado de Federação de Economia e Estatística (1981).

Destes 3.710, 737 registros foram de africanos e 2.963 de nascidos no Brasil. Em outros dez batismos não foi possível identificar a naturalidade, embora em alguns deles fique a desconfiança do historiador de que havia a cumplicidade do padre na tentativa de esconder o ba- 
tismo de um africano ilegalmente escravizado, já que neles não havia nem o nome da mãe nem a data de nascimento do batizando - informações comuns nesse tipo de documentação.

\section{Da obrigação ao significado de batizar}

Conforme as Constituições Primeiras do Arcebispado da Bahia, era uma obrigação do senhor batizar seus escravos. Na verdade, as responsabilidades dos proprietários no que diz respeito às práticas religiosas eram mais amplas, pois eram "obrigados os pais, mestres, amos e senhores a ensinar ou fazer ensinar a doutrina cristã aos filhos, discípulos, criados e escravos" (Vide, Livro 1, Título 2 [II], 2007, p. 2-3, destaques nossos). Para tanto, as Constituições também determinavam que a burocracia eclesiástica local (vigários, curas etc.) "com grande cuidado se informem dos escravos e escravas que em suas Freguesias houver" e "procedam contra seus senhores para que os ensinem ou façam ensinar a Santa doutrina" (Vide, Livro 1, Título 14 [XIV], 2007, p. 21).

Embora as Constituições Primeiras sejam do início do século XVIII, até "meados do século XIX" elas conservaram "muito de sua autoridade do ponto de vista jurídico e eclesiológico", sendo publicadas pela quarta vez (Feitler, Souza, 20ll, p. 11). Com efeito, segundo Manoel J. Porto, a vigência das Constituições e da lei canônica foi estendida para o Brasil independente por Decreto e Resolução, em 1827, e recomendada por Aviso, em 1828 (Porto apud Graham, 2005, p. 253). Como é possível constatar pelos milhares de livros de batismos espalhados nos diferentes recantos do Brasil, muitos dos quais ainda esperando o olhar mais atento dos pesquisadores, no que dizia respeito à relação entre escravos e seus senhores, as normas estabelecidas pelas Constituições continuaram a ser cumpridas por boa parte dos senhores no Oitocentos.

Por isso, tal normativa fez com que se produzisse talvez o maior acervo (leia-se, os registros eclesiásticos - batismos, casamentos e óbitos) sobre parte da vida dos cativos que viveram no Brasil. E, mais importante, esses registros tinham um caráter "individual", algo por vezes de difícil acesso no que diz respeito ao registro da vida dos escravos. Mais: por serem fontes seriais, isto é, massivas e reiterativas, esses documentos se prestam a análises outras que não só qualitativas, como apreciações demográficas, por exemplo. É esta última característica que nos permite a análise que faremos mais à frente.

Por sua vez, de acordo com Eric Wolf e Sidney Mintz, as relações produzidas pelo batismo, além de poder ligar pessoas de diferentes estratos sociais, tinham três dimensões: a que fortalecia os laços do batizando com seus pais biológicos; a que ligava o batizando e 
seus pais espirituais; e a que unia os pais biológicos aos pais espirituais (Wolf, Mintz, 1960). ${ }^{1}$ Mas, no caso dos escravos, qual o significado dos ritos cristãos? Como eles se valiam do regramento eclesiástico, especialmente do batismo, para estabelecer laços sociais diversos?

Conforme José R. Góes, "o batismo foi apropriado pelos escravos de maneira desigual, ou seja, havia aqueles para os quais a cerimônia cristã não parecia estar facilmente disponível”. Nesse sentido, Góes sugere que "os escravos que puderam aproveitá-las [as relações de compadrio] mais frequentemente viveram melhor a experiência do cativeiro" (Goés, 1993, p. 103-104).

Em acordo com a assertiva acima, Cacilda Machado defende que o "compadrio contribuiu para a constituição de diferenças no interior da própria comunidade de escravos e livres de cor" (Machado, 2008, p. 203). Kátia Mattoso ponderou que "em torno da família devem ser buscados os elementos para se compreender as complexas hierarquias sociais, pois a família era o eixo a cuja volta giravam as relações sociais". Para Mattoso, "graças aos laços de parentesco [...] um mulato - às vezes um negro - podia subir na hierarquia social" (Mattoso, 1992, p. 210). E, naquele mundo onde os valores também eram constituídos e informados por uma ordem católica, muitas vezes parentes espirituais faziam parte dessa família - ou do grupo de convivência, pensando de maneira mais ampla.

Não à toa, Ana L. Rios argumenta que "o batismo como um instrumento que criava laços de parentesco (ritual)" era algo "estratégico para os escravos", pois produzia "vínculos duradouros não só entre a criança e os padrinhos, mas também entre estes e os pais naturais". Para a autora, "a exclusão dos senhores desta relação mostra o quão profundamente o contexto do cativeiro influenciou a escolha dos compadres", indicando que o sentido do batismo era entendido "pelos escravos como um rito que criava o parentesco" (Rios, 2000, p. 289). ${ }^{2}$

No entanto, como ficará claro, o parentesco espiritual não se dava apenas com escravos e egressos do cativeiro, embora estes fossem parte importante da composição dos padrinhos e madrinhas. Tal ponderação é fundamental, pois o estudo do compadrio revela estruturas outras como, por exemplo, com quem muitos escravos se relacionavam, resgatando uma visão mais complexa acerca do período escravista brasileiro que a do olhar mecanicista que

${ }^{1}$ Como será possível perceber, neste estudo focamos, por um lado, na análise geral do compadrio e, por outro, no compadrio de africanos batizados. A apreciação do compadrio de escravos nascidos no Brasil, e os laços sociais produzidos a partir dele, apesar de serem maioria e estarem diluídos no total dos registros, fica para outro momento em razão de sua especificidade. Como aponta José R. Góes, "eram os batismos das crianças [...] os que ensejavam o estabelecimento de vínculos múltiplos entre os escravos". Para o autor, "as relações de compadrio criadas ao redor do batismo de crianças escravas era a grande oportunidade onde se tecia a comunidade dos cativos" em determinada localidade (Góes, 1993. p. 117). Concordamos com a especificidade desse fenômeno, todavia, como esperamos que seja possível perceber, nem só do compadrio de escravos nascidos no Brasil se produziam grupos de convívio sólidos.

2 Tradução livre do autor. Acerca do debate sobre a importância do batismo e do compadrio para a história social no Brasil, ver Fragoso, Guedes (2016). 
percebe, em grande medida, o grupo com o qual os cativos conviviam quase que somente conformado por outros escravos, isto é, informado pela condição jurídica.

Por outro lado, grosso modo, a historiografia concorda que se procuravam pais espirituais mais bem posicionados na hierarquia social e, logo, com recursos materiais e simbólicos que pudessem irradiar por toda uma rede de relacionamentos, incluindo, é claro, alguns de seus afilhados, ou seja, buscava-se apadrinhamento "para cima" (Brügger, 2007; Farinatti, 2011). Entretanto, este "para cima" é mais complexo do que aparenta à primeira vista. Por vezes, uma madrinha "santa", aos olhos e crença dos envolvidos no ato do batismo, poderia representar uma aliança "para cima".

Nesse panorama, e em um porto voltado para o Atlântico, onde a dinâmica social e econômica e a movimentação de pessoas eram um tanto diferentes das que ocorriam na maioria das outras localidades do Brasil oitocentista, predominantemente rural, como se processaram as relações de compadrio entre escravos? Havia diferença entre os padrões gerais de compadrio e o de africanos, em específico? Ocorreram mudanças ao longo do tempo e em diferentes contextos históricos? Antes de passarmos para a análise principal, é essencial dizer que o pressuposto defendido aqui é que os escravos, sejam eles africanos ou nascidos no Brasil, utilizaram a associação via compadrio (e outras formas de associação religiosa) como uma maneira de se rearticular na diáspora e no cativeiro, por vezes dentro de um mesmo grupo étnico e, com isso, sobreviver e (re)significar suas vidas. Ao mesmo tempo, o estabelecimento de laços de compadrio, além de vínculos sociais e espirituais, valia como fonte de prestígio para aqueles (mais) chamados para apadrinhar, os quais se destacavam na hierarquia social, tanto dentro, como fora do cativeiro.

\section{Tráfico e batismo de escravos em um porto atlântico}

Como mencionado, entre aproximadamente 1780 e 1850, 3.710 cerimônias de batismo de escravos foram celebradas na igreja de Rio Grande, sendo 737 delas batismos de africanos. No Gráfico l é possível observar a distribuição destes batismos ao longo do tempo.

Nele, também é possível perceber o crescimento da população cativa na localidade. Para tanto, contribuiu não apenas o tráfico atlântico, mas também e fundamentalmente o nascimento de cativos no Brasil. Na verdade, é interessante observar que, geralmente, o crescimento dos batismos de crioulos acompanhava o de africanos - e/ou vice-versa. Infelizmente, boa parte dos registros dos anos de 1847, 1848 e 1850 ainda não foi encontrada, o que faz com que o gráfico apresente uma queda drástica no auge do registro de batismos de africanos, isto é, no momento em que Rio Grande mais recebia escravizados oriundos, em alguma medida, do tráfico atlântico - ao menos da sua fase interna, ou seja, de algum outro porto brasileiro para o RS. 
Importante destacar que esse crescimento e a própria formação de uma sociedade escravista ao sul do império não se processou, por óbvio, de maneira de tranquila e estável. Como em outras partes do Brasil, os escravos estavam atentos a distúrbios e agitações entre a população livre - especialmente no contexto fronteiriço, onde vários conflitos com súditos espanhóis e, depois, com nações vizinhas aconteceram. A título de exemplo, em novembro de 1821, a câmara de Rio Grande enviou ofício ao presidente da província, informando que "o povo da mesma Vila reclamou a prisão de Antônio Manoel Correia da Câmara [...], acusando-o de querer sublevar os negros, prometendo-lhes a liberdade". Em outro momento, acusou-se Antônio Manoel de andar "pelo termo da Vila convocando pessoas brancas e escravos para uma Revolução". Junto com Antônio foram presos o capitão José Joaquim de Castro Amarante e o caixeiro Francisco José Coelho, todos enviados para a capital da província (Antônio, depois, para o Rio de Janeiro). ${ }^{3}$

Conforme o mesmo ofício,

as notícias espalharam-se com a maior rapidez por toda a Província, influindo consideravelmente nos ânimos de seus habitantes brancos e negros, e de tal modo nestes últimos, que fui obrigado a desviar dos seus trabalhos aos Milicianos em uma época, aliás, tão prejudicial às lavouras, afim de não arriscar a segurança deste País.

Os escravos não se sublevaram, mas ao longo do século XIX foram constantes as fugas para o além-fronteira, especialmente depois que a escravidão foi abolida na Banda Oriental (i.e., Uruguai), formação de quilombos e novas tentativas de insurreições (Maestri, 1979, 1984; Petiz, 2006; Al-Alam, Moreira, Pinto, 2013).

Voltando, não obstante essa importância do tráfico, o RS quase não recebia embarcações diretamente da África. O porto de Rio Grande era abastecido por africanos e crioulos advindos, principalmente, de Rio de Janeiro, Salvador e Recife (Berute, 2006; Osório, 2007, p. 219; Aladrén, 2012, p. 51-52). Aliás, o crescimento da entrada de africanos a partir da década de 1830 esteve atrelado ao incremento do comércio com a praça de Salvador (Scherer, 2008). Não à toa, dos 198 (189 deles de nação Nagô ou Mina) batizandos oriundos do golfo do Benin, origem da maior parte dos africanos traficados a partir da Bahia, 105 foram apenas

${ }^{3}$ Antônio M. C. da Câmara, filho de Patrício Correia da Câmara, visconde de Pelotas, havia estudado na Europa, de onde trouxe ideias revolucionárias (não à toa, esteve ao lado dos irmãos Andradas no processo de independência do Brasil e também ao lado dos rebeldes farroupilhas na guerra civil que assolou a província por cerca de dez anos). Arquivo Nacional. Fundo Série Guerras, IG1 167. Todas as demais citações são deste documento, salvo nova referência. 
entre os anos de 1834 e 1850 - números que certamente seriam maiores caso os batismos de 1847,1848 e 1850 estivessem contabilizados. ${ }^{4}$

Gráfico 1 - Frequência dos batismos de escravos, Rio Grande (c. 1780-1850)

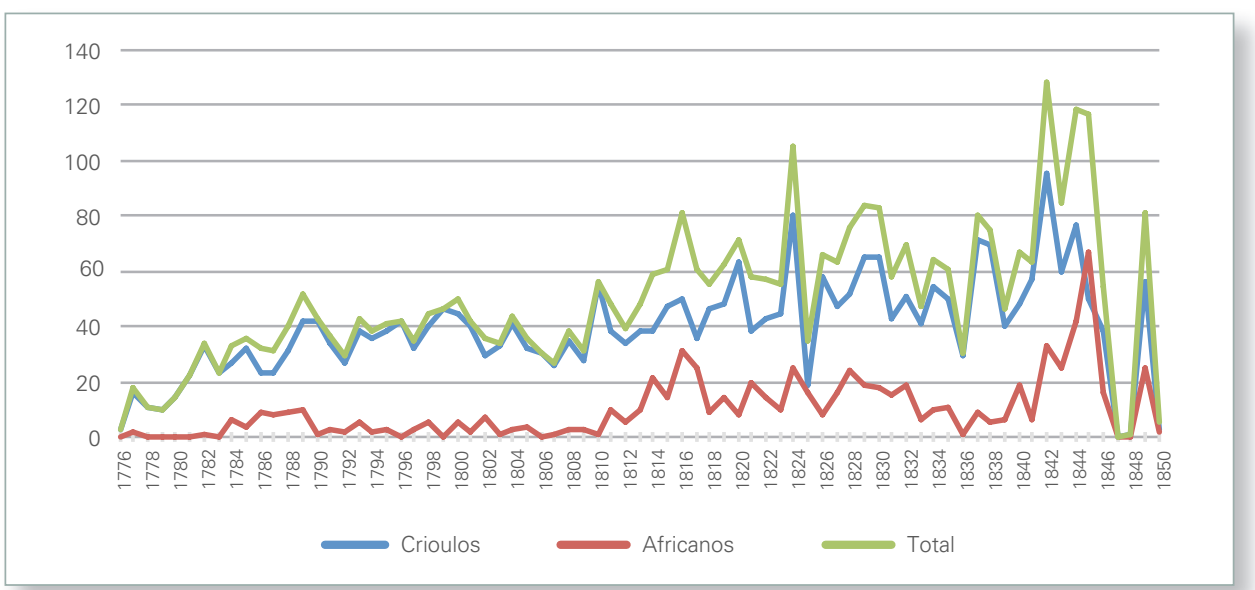

Fonte: Igreja de Rio Grande, livros de batismos, 1776-1850, disponivel em <www.familysearch.com>.

Com efeito, o comércio de escravizados da Bahia para o RS cresceu tanto na década de 1840 que em um ano (1845) mais africanos (67) foram batizados em Rio Grande do que crioulos (51). Desses 67 africanos, 59 tiveram a "nação" indicada e, destes, 42 (ou 71\%) foram identificados como Mina ou Nagô.

\section{O compadrio de escravos na vila de Rio Grande}

Passando para as características, no que diz respeito à condição jurídica, dos padrinhos de cativos, no geral, em 1.464 registros o padrinho foi escravo; em 1.408, livre (ou não teve nenhuma referência em relação à condição jurídica, como, por exemplo, ser egresso do cativeiro, anotada); em 373, forro; em 352, o pai espiritual teve um nome apenas anotado (isto é, sem sobrenome), quando optamos por colocar "s/r" (leia-se, "sem referência", doravante $\mathrm{s} / \mathrm{r})^{5}$ na condição jurídica; e, por fim, em 114 cerimônias não houve padrinho algum. Por

\footnotetext{
${ }^{4}$ Igreja de Rio Grande, livros de batismos, 1776-1850, disponível em www.familysearch.com. Todas as citações de dados agregados em relação aos batismos são dessa fonte, salvo nova ou específica referência.

5 Tal opção metodológica advém da suspeita de que, muitas vezes, esses indivíduos eram forros, ou mesmos escravos, e o padre não indicou sua condição jurídica. Um exemplo é Antônio Mina (africano e padrinho do também africano João,
} 
outro lado, em 1.228 batismos a madrinha foi uma escrava; em 657, livre; em outras 405 cerimônias, uma forra compareceu à pia batismal; em 344, uma santa; em 461, s/r; e, finalmente, em 616 cerimônias não houve madrinha.

Por sua vez, analisando somente os 737 batismos de africanos, em 387 deles o padrinho foi um escravo; em 76, forro; em 98, s/r; em 159, livre; e em 17, não houve padrinho. Já no que diz respeito às madrinhas, em 259 casos a mãe espiritual foi uma escrava; em 93, uma forra; em 90, sem referência; em 76, uma santa; em 55, livres; e em 163 registros, não houve madrinha.

Outro dado interessante é que dos batismos de africanos escravizados, 496 (ou 67,5\%) deles foram do sexo masculino. Tal questão ajuda a explicar o porquê da quantidade de registros sem madrinhas (163) ser significativamente maior do que os sem padrinho (17), dentro de uma lógica de que o padrinho (o que levanta a importância da questão de gênero) seja, em grande medida, o responsável pela (re)inserção social e no mundo do trabalho do seu afilhado. Com efeito, dos 163 casos em que não houve madrinha, 133 deles foram de um batizando do sexo masculino (em apenas 11 registros não houve padrinho) e apenas 30 de batizandas africanas. Por fim, não deve passar despercebido que nos batismos de africanos, quando o grupo em que seriam inseridos tinha certa autonomia na escolha dos padrinhos, estes preferiam fazer uma aliança espiritual com uma "santa" do que com uma pessoa livre.

Portanto, fica patente que, no geral, os escolhidos para apadrinhar cativos também eram escravos. Se somarmos os pais espirituais cativos aos egressos da escravidão e àqueles que provavelmente tinham alguma relação com o cativeiro (os "s/r"), essa representatividade cresce ainda mais.

Contudo, cremos que essa visão geral faz com que se percam particularidades importantes, tanto no que diz respeito à história especifica da região, ao tráfico de escravos para a mesma, assim como quanto à própria demografia (escrava, em particular). Por isso, como tratamos de um período longo, cerca de setenta anos, dividimos o mesmo em três recortes temporais, os quais têm relação tanto com dinâmicas atlânticas e do tráfico de almas, como com dinâmicas internas à capitania/província.

O primeiro vai de 1780 até 1805, período em que a capitania passou a ter uma relação mais orgânica com a economia colonial (devido à produção pecuária, do charque, trigo e a invasão e ocupação definitiva dos Sete Povos das Missões e o espaço geográfico onde ficavam as estâncias dos indígenas), que engloba a chamada por Manolo Florentino "Fase B" (de estabilidade) do mercado atlântico de escravos, momento em que 95 africanos foram batizados na localidade onde, conforme mapas de população, viviam 596 escravos, depois 2.060

Benguela, em 1787), que não teve sua condição anotada e, por isso, entrou na categoria "s/r". Na verdade, cremos que a maioria dos que foram assim categorizados tem alguma relação com o cativeiro. Em: Igreja de Rio Grande, livro de batismos de escravos n. 1, p. 43v, disponível em <www.familysearch.com>. 
e por último 3.196 cativos nos anos de 1780, 1798 e 1802, respectivamente (Marques, 2016, p. 49-51). O segundo recorte vai de 1806 até quase o início da Guerra Civil Farroupilha (1834), abarcando a "Fase A" do comércio atlântico e também a sua aceleração no final da década de 1820, momento em que 375 africanos foram levados à pia batismal e quando a localidade contava com 1.119 escravos, conforme um censo de 1814, e 1.770 cativos em 1819, de acordo com o viajante Auguste de Saint-Hilaire (FEE, 1981, p. 50; Scherer, 2008, p. 24, 27). ${ }^{6}$ Por fim, o terceiro recorte vai da retomada do tráfico atlântico, em sua fase de ilegalidade, até a proibição definitiva desse comércio (1835-1850), período em que uma parte da província esteve em guerra com o Império, contudo, momento em que a intensidade e a característica do tráfico de escravos para a província sofreram algumas mudanças, notadamente com o crescimento do envio de africanos de nação Mina da Bahia para o RS, mudando a configuração da escravidão em boa parte das localidades da província. Neste último recorte, foram batizados 267 africanos e, de acordo com um mapa estatístico de 1842, havia 2.772 cativos, 1.343 deles africanos (ou 48,5\%), em Rio Grande.? Por óbvio, em alguma medida esses recortes são arbitrários e imprecisos, todavia, são um recurso para buscarmos capturar algumas tendências e acompanharmos as mudanças ao longo do tempo.

Dito isso, passemos a análise por recortes, cujo panorama geral está nas Tabelas le 2. Entre c.1780 e 1805 foram realizadas exatas mil cerimônias de batismo de escravos, sendo 95 (9,5\%) de africanos. No geral, apenas 20,5\% dos padrinhos e 19,5\% das madrinhas foram escravos e impressionantes 53\% dos padrinhos foram pessoas livres, enquanto 20,5\% das madrinhas tinham essa mesma condição (em 24,5\% das cerimônias a condição das madrinhas foi "s/r" e em 25,5\% nenhuma mãe espiritual compareceu à pia).

No caso dos batismos de africanos, $23 \%$ dos padrinhos e $17 \%$ das madrinhas foram cativos e 42\% dos padrinhos e 8,5\% das madrinhas eram livres (em 39\% das celebrações não houve madrinha e em $25 \%$ a condição foi s/r). Tanto em termos gerais, quanto nos batismos de africanos, os pais espirituais forros nunca alcançaram $10 \%$ e as madrinhas santas atingiram cerca de $4 \%$ em ambos os casos. Esses altos percentuais de padrinhos livres vão ao encontro do que vários estudos indicaram para diversas regiões do Brasil, em diferentes recortes temporais (Góes, 1993; Schwartz, 2001; Guedes, 2000; Machado, 2007; Farinatti, 2011; Vasconcellos, 2002; Guterres, 2005). No entanto, tal padrão mudou nos recortes seguintes.

\footnotetext{
${ }^{6}$ No censo de 1814, localidades que antes tinham seus cativos contabilizados em Rio Grande, como Pelotas e Piratini, foram contadas separadamente, daí a queda tão brusca no número de cativos. A título de exemplo, juntas, essas duas freguesias contadas com 2.761 escravos neste censo.

7 Jovani Scherer acredita que a população escrava arrolada no mapa tenha sido essencialmente a urbana. De qualquer modo, com o passar dos anos, a população cativa da localidade voltou a crescer, pois em 1856 Rio Grande tinha cerca de 3.650 escravos, mesmo sendo contabilizados separadamente os quase 1.400 escravos de São J. do Norte e Povo Novo (FEE, 1981, p. 66).
} 
Tabela 1 - Condição dos pais espirituais

da totalidade dos batismos de escravos

\begin{tabular}{|c|c|c|c|c|c|c|c|}
\hline $\begin{array}{l}\text { CONDIÇÃO DO } \\
\text { PADRINHO }\end{array}$ & c.1780-1805 & 1806-1834 & $1835-1850$ & $\begin{array}{c}\text { CONDIÇÃO } \\
\text { DA MADRINHA }\end{array}$ & c.1780-1805 & 1806-1834 & $1835-1850$ \\
\hline Escravo & 20,5 & 50 & 40 & Escrava & 19,5 & 39 & 36,5 \\
\hline Forro & 7,5 & 14 & 6 & Forra & 6,5 & 15,5 & 7,5 \\
\hline Livre & 53 & 31,5 & 34 & Livre & 20,5 & 15,5 & 19 \\
\hline $\mathbf{s} / \mathbf{r}$ & 14 & 2,5 & 16,5 & $s / r$ & 24,5 & 3,5 & 15,5 \\
\hline $\begin{array}{l}\text { Não houve } \\
\text { padrinho }\end{array}$ & 5 & 2 & 3,5 & $\begin{array}{l}\text { Não houve } \\
\text { madrinha }\end{array}$ & 25,5 & 15 & 10,5 \\
\hline Santo & - & - & & Santa & 3,5 & 11,5 & 11 \\
\hline Total \% & 100 & 100 & 100 & Total \% & 100 & 100 & 100 \\
\hline $\begin{array}{l}\text { Total de } \\
\text { registros }\end{array}$ & 1.000 & 1.691 & 1.019 & $\begin{array}{l}\text { Total de } \\
\text { registros }\end{array}$ & 1.000 & 1.691 & 1.019 \\
\hline
\end{tabular}

Fonte: elaborada pelo autor a partir de Igreja de Rio Grande, livros de batismos, 1776-1850.

Disponivel em: <www.familysearch.com>.

Tabela 2 - Condição dos pais espirituais

dos africanos batizados

\begin{tabular}{|l|c|c|c|l|c|c|c|}
\hline $\begin{array}{l}\text { CONDIČ̃̃ DO } \\
\text { PADRINHO }\end{array}$ & C.1780-1805 & $\mathbf{1 8 0 6 - 1 8 3 4}$ & $\mathbf{1 8 3 5 - 1 8 5 0}$ & $\begin{array}{c}\text { CONDIC̄̃̃O } \\
\text { DA MADRINHA }\end{array}$ & c.1780-1805 & $\mathbf{1 8 0 6 - 1 8 3 4}$ & $\mathbf{1 8 3 5}-\mathbf{1 8 5 0}$ \\
\hline Escravo & 23 & 66,5 & 42,5 & Escrava & 17 & 40 & 35 \\
\hline Forro & 9,5 & 15,5 & 4 & Forra & 6,5 & 19 & 6,5 \\
\hline Livre & 42 & 14,5 & 24,5 & Livre & 8,5 & 5 & 10,5 \\
\hline s/r & 20 & 2 & 26,5 & s/r & 25 & 3,5 & 20 \\
\hline $\begin{array}{l}\text { Não houve } \\
\text { padrinho }\end{array}$ & 5,5 & 1,5 & 2,5 & $\begin{array}{l}\text { Não houve } \\
\text { madrinha }\end{array}$ & 39 & 24 & 13 \\
\hline Santo & - & - & - & Santa & 4 & 8,5 & 15 \\
\hline Total \% & 100 & 100 & 100 & Total \% & 100 & 100 & 100 \\
\hline $\begin{array}{l}\text { Total de } \\
\text { registros }\end{array}$ & 95 & 375 & 267 & $\begin{array}{l}\text { Total de } \\
\text { registros }\end{array}$ & 95 & 375 & 267 \\
\hline
\end{tabular}

Fonte: elaborada pelo autor a partir de Igreja de Rio Grande, livros de batismos, 1776-1850.

Disponivel em: <www.familysearch.com>.

Entre 1806 e 1834, o percentual de padrinhos e madrinhas escravos cresce exponencialmente: o de padrinhos mais do que duplica, indo a 50\%, e o de madrinhas dobra, perfazendo $39 \%$. Com isso, os padrinhos livres caem para 31,5\%, e as madrinhas, para $15,5 \%$. Outro crescimento significativo foi o de pais espirituais forros: 14\% de padrinhos e 15,5\% madrinhas. Finalmente, as santas vão a 11,5\% das madrinhas. 
Dentre os africanos batizados, o percentual de padrinhos escravos vai a 2 em cada 3 $(66,5 \%)$, e de madrinhas, a 40\%. Destaque novamente para os forros, que ficam acima dos livres: $15,5 \%$ dos padrinhos e 19\% das madrinhas.

O que parecia estar se processando na localidade é um estreitamento e amadurecimento das relações sociais entre escravos e egressos do cativeiro, que passaram a controlar, em certa medida, o mercado do compadrio, conquistando mais autonomia em relação à escolha dos padrinhos. Por óbvio, os senhores sempre mantiverem certa ingerência sobre essa escolha, porém, no jogo das tensões das relações escravistas e na constante negociação entre senhores e escravos (sem pensar em mundos estanques, em que não havia canais de diálogo e, novamente, tensão), os últimos pareciam estar se beneficiando. ${ }^{8}$

Mesmo não querendo forçar o encaixe do postulado acima com a tese de Norbert Elias, em Os estabelecidos e os outsiders, a ideia geral da obra de Elias serve como um insight, como um parâmetro para reflexão, e nada mais do que isso (Elias, 2000). De novo, ao que parece, a primeira geração de escravos (alguns deles já forros), formada por crioulos e africanos, já estabelecida e com laços sociais mais significativos, serviu, em grande medida, como padrinhos e madrinhas da nova geração de escravos, tanto de nascidos no Brasil quanto de africanos. ${ }^{9}$

Da mesma forma, esse crescimento de libertos entre os padrinhos, apesar da queda entre 1835 e 1850 (muito embora eles possam estar dentre os s/r, que tiveram seus maiores percentuais justamente nesse momento, especialmente no caso dos padrinhos homens), provavelmente esteja em diálogo com um dos principais fenômenos do escravismo brasileiro: a passagem da escravidão para liberdade. Daí não só o crescimento de libertos entre os pais espirituais e também do ponto de vista demográfico, mas, e tão fundamental quanto, o crescimento da sua importância enquanto grupo com uma função social relevante. Conforme João Fragoso, "o apadrinhamento, entendido como parentesco ritual numa sociedade em que a vida religiosa se confundia com a social" tem um "papel vital no cotidiano e pode ser encarado como um índice que mede o peso dos grupos na organização social considerada" (Fragoso, 2014, p. 249)..$^{10}$

No último recorte, entre 1835 e 1850, o número de pais espirituais escravos regride para

\footnotetext{
${ }^{8}$ Sobre o debate da existência de uma cultura escrava autônoma e, também por isso, de resistência (quase que constante) aos interesses senhoriais, ou, ao contrário, da interlocução entre estes dois grupos sociais na produção de um contexto social complexo, ver Gutman (1976); Genovese (1988). Um ótimo resumo desta discussão pode ser encontrado em Machado (1988). Ver também Reis, Silva, (1999).

9 No mesmo sentido, isto é, acerca das transformações e adaptações geracionais (ou do processo de "ladinização") de africanos e seus descendentes a sociedades escravistas e católicas, ocorridas através do tempo, mas para um recorte anterior ao enfocado aqui, ver Wheat (2016).

10 João Fragoso notou, para o Rio de Janeiro do século XVIII, que "com o amadurecimento da região, o número de padrinhos forros tende a aumentar" (Fragoso, 2014, p. 249 e 'nota 11' na página 300).
} 
$40 \%$ entre os padrinhos e $36,5 \%$ nas madrinhas, assim como o de forros (6\% e 7,5\%, respectivamente). A representatividade dos padrinhos livres cresce levemente para 34\%, bem como as madrinhas (19\%), com a invocação de santa mantendo-se na casa dos $11 \%$.

Dentre os africanos batizados, os padrinhos escravos caíram de $66,5 \%$ para $42,5 \%$, e as madrinhas, de $40 \%$ para 35\%. Já entre os pais espirituais forros, os percentuais caíram de $15,5 \%$ e $19 \%$ para $4 \%$ e $6,5 \%$, respectivamente. Pode ser que muitos forros estejam entre os $26,5 \%$ de padrinhos e $20 \%$ de madrinha $s / r$, sendo, portanto, mais uma falta de cuidado do padre em anotar tal condição. Todavia, essa queda significativa entre padrinhos cativos e forros (apesar, de novo, da possibilidade destes últimos estarem diluídos entre os s/r ou mesmo nos livres) pode ter outra razão.

Como mencionado anteriormente, a configuração do tráfico para o RS se altera a partir de meados da década de 1830. Até então, havia um predomínio de escravos oriundos do Rio de Janeiro, dentre os quais a maioria de africanos da África Central. Entretanto, com o crescimento da produção pecuária e do charque, a demanda por escravos passou a ser suprida, em boa medida, pela praça de Salvador, de onde provinham principalmente Minas e Nagôs. Tal fenômeno encontra eco nos batismos: dos 375 africanos batizados entre 1835 e 1850, em 195 há a designação da nação; e nada menos do que 99, ou 51\%, são Minas ou Nagôs.

Uma primeira questão que se abre é: esses africanos oriundos da praça de Salvador já haviam sido batizados na Bahia? Ou eram originários direto do tráfico transatlântico? Caso alguns deles estivessem sendo rebatizados, a norma eclesiástica estaria sendo desrespeitada." Contudo, cremos que alguns dos africanos Mina comercializados para o RS já vinham batizados (sendo muito difícil responder se eram levados ou não novamente à pia batismal no RS), por um motivo bastante singelo - e que possivelmente fez com que os senhores sul-rio-grandenses passassem a ter um olhar mais cuidadoso sobre a produção de laços de compadrio de seus escravos africanos, especialmente a partir de meados da década de 1830.

O leitor mais atento já deve ter percebido que o processo descrito acima é contemporâneo à Revolta dos Malês, que agitou Salvador no início de 1835 (Reis, 2003). Por isso, não tardou para as autoridades da província começarem a se alarmar com a vinda, via tráfico interno, de cativos que participaram da revolta - e que, em tese, provavelmente já haviam sido batizados e produzido laços sociais em Salvador.

Em fevereiro de 1835, os vereadores de Pelotas, cidade vizinha a Rio Grande e maior centro charqueador da província, enviaram um ofício para a presidência da província. Nela,

\footnotetext{
${ }^{11}$ Difícil saber o quanto os padres estavam atentos em seguir as regras das Constituições no que diz respeito à vedação da repetição do batismo. No início da década de 1780, em Vacaria, freguesia no extremo norte do RS, o padre tomou cuidado e batizou "sob condição" Antonio, gentio da Guiné, com o qual se comunicou através de "intérpretes". Antonio dizia "ser pagão e que nunca fora batizado". Diocese de Vacaria. Registros de batismo de Vacaria, livro 1, p. 24. Disponível em: <www.familysearch.com>.
} 
relataram que já haviam sido informados dos "acontecimentos que ali [Cidade de Salvador] ocorreram" em janeiro. Além disso, alertaram a presidência que

sendo esta Província [o RS] ordinariamente o receptáculo dos escravos de má conduta que d'outras Províncias do Império vem a vender [...]; e sabendo esta Câmara Municipal pelas ditas cartas particulares, que se dirigem da referida cidade da Bahia porção de escravos Nagôs, e açás para aqui serem vendidos, e já hé de acreditar que elles sejão dos implicados naquella insurreição, e os seus donos os subtraihdo á vingança das leis, ou queirão [deles] ver-se livres [...]; e sendo evidente que se taes escravos vieram, serão vendidos /a maior parte/ para as xarqueadas que existem neste Município, onde [...] contem de dous a tres mil captivos, quasi en contacto huns dos outros, pela proximidade em que se ação ditas xarqueadas, receando-se deste modo que elles venham emgrossar o número dos desmoralizados, e tentarem desordens (Maestri, 1984, p. 131).

Por fim, os vereadores solicitavam que os escravos vindos da Bahia "fossem depositados na vila de Rio Grande com segurança, a fim de que se procedesse a exames para serem reenviados e entregues às autoridades daquela Província" caso ficasse comprovado que haviam participado da revolta (Correia, 2007, p. 17). O aventado aqui é que, talvez, parte dos senhores tenha ficado mais rigorosa na escolha (ou na permissão via negociação) de quem poderia ou não estabelecer laços de compadrio com seus cativos. Porém, isto não impossibilitou a formação e uma comunidade baseada na identidade étnica (Mina) na localidade nem o protagonismo destes na conquista da liberdade, para o que o compadrio parece ter contribuído.

Jovani Scherer, cruzando informações das alforrias, inventários, testamentos, processos-crime, dentre outras fontes, encontrou vestígios de uma bem tramada comunidade de africanos de nação Mina em Rio Grande. Uma comunidade que agregava e não excluía nascidos no Brasil ao mesmo tempo que preservava e praticava antigos cultos e rituais de um passado em comum, reconfigurando elementos étnicos na diáspora (Scherer, 2008, cap. 4).

Alguns dos fios da reconstrução dessa comunidade foram fragmentos da trajetória do africano Mina Jorge Cipriano Rodrigues Barcelos, ex-escravo do comendador Cipriano Rodrigues Barcelos. Em um dos tantos episódios narrados por Jovani Scherer, depois do seu escravo Antônio, de nação haussá, ser acusado de participar de um roubo em 1846, a casa de Jorge é alvo de um auto de busca e apreensão. Nele, é descrito que Jorge Cipriano alugava quartos de sua residência para outros africanos Mina, dentre eles Fabrício de Magalhães e Belchior, e para a Nagô Carlota, o que evidencia para o autor que um dos "critérios utilizados por africanos ocidentais na seleção dos parceiros de moradia" era o "parentesco étnico". Em outro momento, Jorge foi testemunha junto com outros quatro africanos forros, dois deles Mina-Nagô, do testamento nuncupativo (i.e., feito oralmente) de Maria do Bonfim, companheira de muitos anos do Mina Joaquim de Antiqueira (Scherer, 2008, p. 147-150). 
Outro vestígio localizado por Jovani Scherer encontra-se no inventário de Maria Balbina da Conceição, aberto em 1859. Além de alguns bens imóveis, foi listado "um tambor de negros de nação". O autor não encontrou nenhuma indicação direta do passado escravo de Maria Balbina ou de seu marido, Manoel Antônio de Abreu, contudo, a pista do "tambor de negros de nação" o faz sugerir não só essa relação, mas também que a casa de Maria Balbina pudesse ser um ponto de encontro para prática de rituais - ou "batuques", culto afro-ocidental - africanos (Scherer, 2008, p. 170-174).

Também encontramos os africanos Mina Jorge Cipriano, Fabrício de Magalhães, Joaquim de Antiqueira, provavelmente Belchior e Carlota, Balbina Maria da Conceição e seu marido nos batismos, em momentos que os laços espirituais pareciam reforçar a formação de grupos de convívio, mesmo que hierarquizados, entre indivíduos de uma mesma nação. Em dezembro de 1844, Jorge aparece como senhor no batismo de Joana, africana Nagô, a qual teve os "pretos" (que entraram na categoria s/r na condição jurídica) Sabino e Maria como padrinhos. No mesmo dia, Jorge serviu como padrinho da Mina Firmina, escrava batizanda de Maria Joaquina Francisca. Em novembro do ano seguinte, exatamente no ano em que muitos africanos, principalmente de nação Mina, estavam desembarcando em Rio Grande, Jorge comparece à pia novamente como senhor, agora da Mina Josefa, que teve como padrinhos "Joaquim e Florinda”. Poucos dias depois dessa cerimônia, Fabrício Magalhães serviu como padrinho do crioulo Jordão, filho de Jerônima, escrava de João Dias Vianna. Em setembro de 1849, Jorge volta a ser padrinho, agora ao lado de sua companheira Mariana Monteverde, de Daniel, filho da africana Mina Lauriana, escravos Manoel Pereira Bastos. Por fim, Joaquim de Antiqueira também compareceu à pia como senhor, em janeiro de 1845, da africana Mina Felicidade, que teve como padrinhos os "pretos libertos" Belchior e Carlota (talvez os mesmos Mina e Nagô, respectivamente, que alugavam quartos de Jorge Cipriano).12

Por outro lado, a suspeita de Jovani Scherer acerca da proprietária do "tambor de negros de nação" parece estar correta. Balbina Maria da Conceição e seu marido Manoel Antônio de Abreu foram convidados diversas vezes para apadrinhar: em 1844, Balbina foi madrinha de Antônia, filha da africana de nação Angola Rosa; em 1845, novamente Balbina serviu de madrinha do africano Mina Emiliano; em 1846, Balbina compareceu duas vezes à pia, uma ao lado do seu esposo Manoel de Abreu para batizar Joaquim, filho legítimo de Maria Doroteia e do africano Cabinda Custódio, e outra para servir de mãe espiritual de Balduíno, filho da crioula Maria; por fim, em novembro de 1849, Manoel A. de Abreu serve de padrinho de Moisés, filho da crioula Albana. E, com efeito, em nenhum desses registros o padre indi-

12 Diocese de Rio Grande. Registros de batismo de Rio Grande, livro 5, p. 184v, 185, 185v e 191v; livro 13, p. 24v. Disponível em: <www.familysearch.com>. A informação de que Mariana Monteverde era companheira e depois, em 1879, herdeira de Jorge Cipriano está em: Scherer (2008, p. 166). 
cou algo sobre a cor ou a experiência passada no cativeiro de ambos. No entanto, no mesmo ano do batismo de Albana, 1849, Balbina e Manoel levaram sua filha Eufrásia para receber os santos óleos. E nesse registro o padre anota que a batizanda era "crioula" e "filha legítima de Manoel Antônio de Abreu, "preto Mina”, e Balbina Maria da Conceição, natural desta província; foram padrinhos Malaquias José e Eufrásia Maria da Conceição". ${ }^{13}$

Não deixa de ser curioso como a produção da hierarquia se processava e transbordava, ou não, para os documentos. Quando foram convidados para apadrinhar, algo prestigioso em uma sociedade católica, Balbina e Manoel não tiveram quaisquer características e/ou condição registrada, porém, quando do batismo de sua filha, a mesma foi destacada como crioula e seu pai teve lembrada a condição de africano.

Praticamente todos os africanos Mina mencionados nos últimos parágrafos eram forros. Na verdade, este foi um dos traços mais marcantes dos africanos ocidentais em Rio Grande: o seu protagonismo na conquista da liberdade. Conforme Jovani Scherer, das 356 cartas de manumissão de africanos arroladas entre 1812 e 1865, 35,5\% foram de nação Mina e 12\% Nagôs, seguidos de Benguelas e Congos, com 10,5\% e 8\% respectivamente (Scherer, 2008, p. 117).

E chegamos a outra intersecção entre os temas tratados até aqui: se o compadrio, por um lado, produzia laços sociais que tornavam o cativeiro menos penoso, por outro, muitas vezes, potencializava as chances de liberdade. Em Rio Grande, diversos batizandos foram libertos na pia e, muito embora o padre não tenha anotado o protagonismo dos padrinhos em nenhuma delas, cremos que em alguns casos ele estava lá, mesmo que implícito. A título de exemplo, no ano de 1783 em Estreito, freguesia que pertenceu a Rio Grande por quase todo o recorte temporal deste estudo, o padre Pedro Pereira anotou no batismo de Esméria, filha natural de Margarida, que o senhor "a dava por forra e livre por haver recebido da mão do padrinho [João Carreira Leal] dezenove mil e duzentos”. Na vizinha São José do Norte, freguesia de Rio Grande até a década de 1830, no mês de julho de 1827, Antônio, filho legítimo de Maria, escrava de Ana Lagos, e do preto forro Fernando Pereira, teve sua liberdade anotada no registro de batismo pelo padre em razão do ato do batismo

disseram os padrinhos que eles haviam forrado a dita criança pela quantia de vinte e cinco mil e seiscentos que tinham entregado a sobredita sua senhora; O que a mesma

\footnotetext{
${ }_{13}^{13}$ Diocese de Rio Grande. Registros de batismo de Rio Grande, livro 5, p. 178, 189, 189v e 193v; livro 13, p. 26v e 209. Disponível em: <www.familysearch.com>. Creio que Balbina serviu por duas vezes como madrinha na vizinha Pelotas, ambas no ano de 1831, o que demonstraria não só o amplo leque de relações produzidos pela dona do "tambor", mas também a mobilidade espacial da mesma. Arquidiocese de Pelotas. Registros de batismo de Pelotas, 1831, p. 373 e 381 . Agradeço aos colegas Natália Pinto e Jonas Vargas por me franquearem acesso aos seus bancos de dados dos batismos de Pelotas.
} 
me certificou por uma Carta que me escreveu na qual Ordenava que a sobredita criança desde a pia fosse Declarada forra. ${ }^{14}$

Por seu turno, as descrições das cartas de alforria em cartório foram mais generosas com o historiador no sentido de descrever o protagonismo dos pais espirituais. Encontramos, para Rio Grande no período em análise, seis manumissões em que foi anotada a ação direta do padrinho e/ou da madrinha na obtenção da liberdade. Em 1818, Manoel José da Silva libertou Felisbina "mediante pagamento de $70 \$ 400$ pelas mãos dos padrinhos". Em 1840, a madrinha da recém-nascida Maria Delfina pagou $700 \$ 400$ a Veridiana de Castro Feijó pela sua liberdade. Em 1849, José Joaquim Soares Coimbra descreve que alforriou Isabel de 2 anos de idade, "filha de minha escrava Emília de nação Mina", em função de ter "recebido cem mil réis de Narcisa de São José Mandiá e Paulo José Domingos, madrinha e padrinho de batismo da dita crioulinha". ${ }^{5}$

Esses casos ilustram o quanto o compadrio poderia ser útil ao batizando, entretanto, os laços e obrigações morais produzidos a partir dele não tinham uma via apenas. Jovani Scherer narrou o caso do africano forro de nação Mina Manoel Francisco Bento que, no seu testamento, de 1860, descreveu suas vontades, tendo como testemunha (e compromisso em cumpri-las), além de outros dois africanos ocidentais, o seu afilhado João da Rocha, também Mina, que atestou "ser afilhado de batismo do falecido preto forro Manoel Bento e de sua mulher" (Scherer, 2008, p. 155-156). Confirma-se, assim, mais uma vez, a distinção do traço étnico na escolha do padrinho, bem como a forte e longa duração dos vínculos produzidos na pia batismal. ${ }^{16}$

Por outro lado, a vivência religiosa dentro dos quadros do catolicismo não servia apenas para a produção de laços sociais positivos, mas também podia ser palco de dissensos. Em um conflito que se estendeu por anos a fio (tendo início provavelmente em 1814), indo parar nas mãos do capitão-geral da Capitania do Rio Grande do Sul, na Mesa de Consciência e Ordens e do próprio rei Dom João, os irmãos "pardos e crioulos forros" da Irmandade de Nossa Senhora da Conceição de Rio Grande reclamavam que desde 1814 a imagem da mes-

\footnotetext{
14 Encontramos mais de quarenta libertos na pia, contudo, como não consultamos todos os livros de batismos de pessoas livres, este número certamente é maior, pois o forro durante o ato de batismo muitas vezes tinha seu assento registrado junto aos livres. Para o batismo de Estreito: Diocese de Rio Grande. Registros de batismo de Estreito, livro 2, p. 40. Para o de São José do Norte: Diocese de Rio Grande. Registros de batismo de São José do Norte, livro 2, p. 62. Disponíveis em: $<$ www.familysearch.com>.

${ }^{15}$ Para todas as seis alforrias: Arquivo Público do Estado do Rio Grande do Sul. Livros notariais. Livro s/n (1812-1814), p. 85; Livro 18 (1816-1819), p. 92v. Livro 13 (1839-1840), p. 36 e 39v; Livro 17 (1848-1855), p. 24v e 87v.

16 Sobre tal questão, ver também Mortari (2007). Sobre a produção de laços sociais e afetivos dos africanos Minas em diferentes regiões do Brasil, ver Líbano, Gomes (2001); Reis (2003); Faria, (2004); Moreira (2011); Pinto (2012); Farias (2015).
} 
ma santa estava afixada no Altar da Irmandade do Rosário, o qual ficava junto à Matriz da cidade. ${ }^{17}$ Porém, receosos que a Irmandade do Rosário, a qual

pertencia o Altar, pretenda por sinistras instigações constranger os suplicantes a tirar dele sua imagem [...], recorrem estes a Vossa Majestade para que por efeitos da Sua Alta Piedade lhes faça Graça de Mandar que a sobredita Imagem de Nossa Senhora da Conceição se conserve, como até agora no mencionado Altar da do Rosário, com o que se [acalentarão] as perturbações, de que eles se temem em dano do Culto Divino, que assim procuram manter e aumentar.

Provocados pela Mesa de Consciência e Ordens, os irmãos da Irmandade do Rosário dos Pretos de Rio Grande alegam surpresa com o processo aberto pelos "Irmãos Pardos e Pretos forros da Irmandade de Nossa Senhora da Conceição”, alegando que desejavam apenas que estes assinassem um "Termo" para que "em tempo algum se" achassem de

posse do referido Altar do Rosário como já aconteceu em outro tempo com a Ordem Terceira de Nossa Senhora do Monte do Carmo, que colocando-se no nosso Altar a Imagem de Nossa Senhora do Monte do Carmo, e fazendo-se [...] todos os altos da Ordem, passados alguns anos quiseram os Irmãos da Terceira do Carmo chamar-se a posse do Altar e só convencidos Judicialmente é que desistiram da sua iníqua pretensão, sendo expulsos do Altar.

Não indo aos pormenores do resultado da contenda, a qual estamos analisando em outro estudo, na verdade a mesma fortalece o argumento central do aqui analisado e narrado - o de que ritos (como os batismos) e espaços religiosos (como as irmandades) serviam para a produção de laços sociais diversos, os quais ajudavam a minorar as agruras do cativeiro e também potencializavam as chances de sair dele com a alforria. Contudo, para que este entendimento seja plausível é preciso que a compreensão de como se processavam a produção de identidades naquele contexto não tenha como único recorte a condição jurídica ou mesmo a experiência de ter passado pelo cativeiro. Sendo mais claro, a condição escrava (ou do passado escravo de um indivíduo) não eliminava conflitos entre pessoas na mesma condição.

${ }^{17}$ Arquivo Nacional. Mesa de Consciência e Ordens - Irmandades, c. 291, p. 4. Todas as próximas citações são deste documento, salvo nova referência. 


\section{Considerações finais}

Em um primeiro momento, pode-se pensar que a realização de cerimônias de batismos e o próprio registro dos mesmos seguia apenas uma norma (as Constituições Primeiras) ou o interesse senhorial em registrar sua posse. Porém, não parece ter sido tão simples assim.

Em uma sociedade predominantemente católica, em que o regramento social, mesmo que costumeiro, era regido em grande medida pela vida religiosa, podia ser de interesse dos escravos também a (re)inserção social via ritos cristãos, tanto para estabelecer vínculos sociais mais amplos, quanto para buscar conforto na fé e na crença, mesmo que mescladas com outras tradições e culturas religiosas. E isso inclusive para os africanos. Três exemplos são significativos, tanto sobre o que estamos comentando, como quanto a uma suposta subnotificação do registro de batismos de africanos: Maria (em 1840), Joaquina Angela (1848), Candido (1850), todos oriundos da África, só foram batizados já forros. ${ }^{18}$

Por sua vez, a mudança estrutural na escolha dos padrinhos (isto é, a transformação da condição jurídica dos pais espirituais) ao longo do tempo também indica que o ato de batizar não era apenas mais um protocolo. Assim, o crescimento de escravos e forros entre os padrinhos ilustra que cativos, libertos e seus pares estavam atentos às possibilidades de produção de grupos e de laços sociais, os quais poderiam ser acionados em momentos específicos, como quando de algum conflito ou mesmo na busca pela liberdade.

Por fim, pode-se pensar que os batismos aqui analisados servem, em grande medida, para entender a produção de laços sociais entre nascidos no Brasil, já que apenas 20\% deles são de africanos. Contudo, uma possível tentativa de preservação da herança cultural e étnica africana via laços de compadrio não deve ser somente percebida e apreendida por meio dos registros de batismos de africanos.

Com efeito, dos 2.963 registros de batismos de crioulos, em 1.825 (ou 61,5\%) foi possível identificar a procedência da mãe do batizando - por óbvio, há aqui diversos casos de repetição de uma mesma mãe, mas o que não invalida o que queremos abordar (já que tal desvio acontece tanto para mães africanas, quanto para mães nascidas no Brasil). Destes 1.825, 1.125 (ou 61,5\%) eram africanas! Dentre as 1.125, 889 (ou 79\%) tiveram sua "nação" especificada: nada menos do que 84,5\% eram da África Central; 12,5\% da Costa da Ocidental (quase todas Mina ou Nagô); e 3\% da Costa Oriental (quase todas Moçambique).

Nesse sentido, a produção de laços de compadrio entre escravos era mais complexa, não

${ }^{18}$ A única que teve sua nação anotada foi Joaquina Angela, oriunda de Cabinda. Igreja de Rio Grande, livro 5, p. 130v, e livro 14, p. 193v e 230v, disponível em: <www.familysearch.com>. Sobre este assunto, é significativo o batismo da africana Mina Luísa, em Bagé, na fronteira sul do Rio Grande do Sul, em que a mesma cita os nomes - africanos - de seus pais. Luísa foi batizada em 1872, ou seja, claramente foi uma escolha sua a busca pelo batismo. 
atendendo apenas a uma lógica orientada pelo fato do batizando ser crioulo ou africano. Certo é que os escravos, de distintas formas, aproveitaram a associação via laços espirituais para diminuir o tormento do cativeiro e/ou da experiência de viver como livre/liberto em uma sociedade onde africanos e seus descendentes estavam em alguma medida inferiorizados e estigmatizados social e hierarquicamente.

\section{Referências}

ALADRÉN, Gabriel. "Sem respeitar nem tratados": escravidão e guerra na formação histórica da fronteira sul do Brasil (Rio Grande de São Pedro, c. 1777 - 1835). Tese (Doutorado) - Universidade Federal Fluminense, Niterói, 2012.

AL-ALAM, Caiuá C.; MOREIRA, Paulo R. S.; PINTO, Natália G. Os Calhambolas do General Manoel Padeiro: práticas quilombolas na Serra dos Tapes (RS, Pelotas, 1835). São Leopoldo: Oikos, 2013.

BERUTE, Gabriel S. Dos escravos que partem para os portos do sul: características do tráfico negreiro do Rio Grande de São Pedro do Sul, c.1790-c.1825. Dissertação (Mestrado) - Universidade Federal do Rio Grande do Sul, Porto Alegre, 2006.

BRÜGGER, Sílvia M. J. Escolhas de padrinhos e relações de poder: uma análise do compadrio em São João del Rei (1736-1850). In: CARVALHO, José M. Nação e cidadania no Império. Rio de Janeiro: Civilização Brasileira, 2007.

CORREIA, Sílvio M. de S. Africanos na Província de São Pedro (1835-1848): quanto vale a liberdade? Anais do $3^{\circ}$ Encontro Escravidão e Liberdade no Brasil Meridional, Florianópolis, 2007. Disponível em: ‘http://www.escravidaoeliberdade.com.br/site/images/ Textos $3 /$ silvio\%20marcus $\% 20$ de $\% 20$ souza $\% 20$ corres.pdf). Acesso em: 21 jan. 2020.

ELIAS, Norbert. Os estabelecidos e os outsiders: sociologia das relações de poder a partir de uma pequena comunidade. Rio de Janeiro: Zahar, 2000.

FARIA, Sheila de Castro. Sinhás pretas, damas mercadoras: as pretas minas nas cidades do Rio de Janeiro e de São João Del Rey (1700-1850). Tese (Concurso para Profes- sor Titular em História do Brasil) - Universidade Federal Fluminense, Niterói, 2004.

FARIAS, Juliana B. Mercados minas: africanos ocidentais na praça do mercado do Rio de Janeiro (1830-1890). Rio de Janeiro: Prefeitura do Rio de Janeiro/Arquivo Geral da Cidade, 2015.

FARINATTI, Luís A. E. Confins meridionais: famílias de elite e sociedade agrária na fronteira sul do Brasil (18251865). Santa Maria: Editora UFSM, 2010.

FARINATTI, Luís A. Relações parentais de escravos, libertos e indígenas na Fronteira Meridional (18171844): Primeiras notas de pesquisa. Anais do V Encontro Escravidão e Liberdade no Brasil Meridional. Porto Alegre, 2011.

FEE. Federação de Economia e Estatística. De Província de São Pedro a Estado do Rio Grande do Sul - censos do RS 1803-1950. Porto Alegre: FEE, 1981.

FEITLER, Bruno; SOUZA, Evergton S. Introdução. In: FEITLER, Bruno; SOUZA, Evergton S. (Orgs.). A Igreja no Brasil: normas e práticas durante a vigência das Constituições Primeiras do Arcebispado da Bahia. São Paulo: Unifesp, 2011. p. 9-23.

FRAGOSO, João. Elite das senzalas e nobreza da terra numa sociedade rural do Antigo Regime nos trópicos: Campo Grande (Rio de Janeiro), 1704-1741. In: FRAGOSO, João; GÔUVEA, Maria de F. (Orgs.). O Brasil Colonial, 1720-1821. v. 3. Rio de Janeiro: Civilização Brasileira, 2014.

FRAGOSO, João, GUEDES, Roberto (Orgs.). História social em registros paroquiais: Sul-sudeste do Brasil, séculos XVIII-XIX). Rio de Janeiro: Mauad X, 2016.

GENOVESE, Eugene D. A terra prometidd: o mundo que os escravos criaram. Rio de Janeiro: Paz e Terra, 1988. 
GÓES, José R. O cativeiro imperfeito: um estudo sobre a escravidão no Rio de Janeiro da primeira metade do século XIX. Vitória: Lineart, 1993.

GOMES, Luciano C. Camponeses e pequenos escravistas: estrutura econômica, reprodução social e vínculos extradomicilares de produtores rurais em Porto Alegre e Viamão, décadas finais do século XVIII. Tese (Doutorado) - Universidade Federal do Rio Grande do Sul, Porto Alegre, 2018.

GRAHAM, Sandra L. Caetana diz não: histórias de mutheres da sociedade escravista brasileira. São Paulo: Companhia das Letras, 2005.

GUEDES, Roberto. Na pia batismal. Família e compadrio entre os escravos na freguesia de São José do Rio de Janeiro (primeira metade do século XIX). Dissertação (Mestrado) - Universidade Federal Fluminense, Niterói, 2000.

GUTERRES, Letícia B. S. Escravidão, família e compadrio ao sul do Império do Brasil: Santa Maria (1844-1882). Tese (Doutorado) - Universidade Federal do Rio de Janeiro, Rio de Janeiro, 2013.

GUTMAN, Herbert. The black family in the slavery and freedom, 1750-1925. New York: Vintage, 1976.

KÜHN, Fábio. Breve história do Rio Grande do Sul. Porto Alegre: Leitura XXI, 2004.

LÍBANO, Carlos E.; GOMES, Flávio. "Com o pé sobre um vulcão": Africanos Minas, identidades e a repressão antiafricana no Rio de Janeiro (1830-1840). Estudos Afro-Asiáticos, Rio de Janeiro, n. 2, v. 23, p. $1-44,2001$.

MACHADO, Maria H. P. T. Em torno da autonomia escrava: uma nova direção para a história social da escravidão. Revista Brasileira de História, (São Paulo), v. 8, n. 16, p. 143-160, mar.-ago., 1988.

MACHADO, Cacilda. Compadrio de escravos \& paternalismo: o caso da Freguesia de São José dos Pinhais (PR), na passagem do século XVIII para o XIX. Anais do III Encontro Escravidão e Liberdade no Brasil Meridional. Florianópolis, 2007.

MACHADO, Cacilda. A trama das vontades: negros, pardos e brancos na produção da hierarquia social do Brasil escravista. Rio de Janeiro: Apicuri, 2008.
MAESTRI, Mário. Quilombos e quilombolas em terras gaúchas. Porto Alegre, Caxias: EST/UCS, 1979.

MAESTRI, Mário. O escravo no Rio Grande do Sul: a charqueada e a gênese do escravismo gaúcho. Porto Alegre: EST/UCS, 1984.

MARQUES, Rachel dos S. Para além dos extremos: homens e mulheres livres e hierarquia social (Rio Grande de São Pedro, c.1776-c.1800). Tese (Doutorado) - Universidade Federal do Paraná, Curitiba, 2016

MATTOSO, Kátia de Q. Bahia, século XIX - uma província no Império. Rio de Janeiro: Nova Fronteira, 1992.

MOREIRA, Paulo R. S. Uma escola corânica de pretos minas: experiências de etnicidade, alforria e família entre africanos (Porto Alegre /RS - 1748 / 1888). Actas de las Segundas Jornadas de Estudios Afrolatinoamericanos del GEALA, Buenos Aires: Mnemosyne, 2011. [CD-ROM]

MORTARI, Cláudia. Os africanos de uma vila portuária do sul do Brasil: criando vínculos parentais e reiventando identidades. Desterro, 1788/1850. Tese (Doutorado) Pontifícia Universidade Católica do Rio Grande do Sul, Porto Alegre, 2007.

OSÓRIO, Helen. Apropriação da terra no Rio Grande de São Pedro e a formação do espaço platino. Dissertação (Mestrado) - Universidade Federal do Rio Grande do Sul, Porto Alegre, 1990.

OSÓRIO, Helen. O império português ao sul da América: estancieiros, lavradores e comerciantes. Porto Alegre: Editora da UFRGS, 2007.

PETIZ, Silmei de S. Buscando a liberdade: as fugas de escravos da província de São Pedro para o além-fronteira (1815-1851). Passo Fundo: UPF, 2006.

PINTO, Natália G. A bênção compadre: experiências de liberdade e parentesco em Pelotas (1830-1850). Dissertação (Mestrado) - Universidade do Vale do Rio dos Sinos, São Leopoldo, 2012.

REIS, João José. Rebelião escrava no Brasil: a história do levante dos Malês em 1835. São Paulo: Companhia das Letras, 2003.

REIS, João José; SILVA, Eduardo. Negociação e conflito: a resistência negra no Brasil escravista. São Paulo: Companhia das Letras, 1999. 
RIOS, Ana M. L. The politics of kinship. Compadrio among slaves in Nineteenth-Century Brazil. The History of Family. An International Quarterly, v. 5, n. 3, p. 287-298, 2000.

SCHERER, Jovani de S. Experiências de busca da liberdade: alforria e comunidade africana em Rio Grande, século XIX. Dissertação (Mestrado) - Universidade do Vale do Rio dos Sinos, São Leopoldo, 2008.

SCHWARTZ, Stuart B. Escravos, roceiros e rebeldes. Bauru: Edusc, 2001.

VARGAS, Jonas M. Os Barões do charque e suas fortunas: um estudo sobre as elites regionais brasileiras a partir de uma análise dos charqueadores de Pelotas (Rio Grande do Sul, séc. XIX). São Leopoldo: Oikos, 2016.
VASCONCELLOS, Marcia C. de. O compadrio entre escravos em uma comunidade em transformação (Mambucaba, Angra dos Reis, século XIX). Afro-Ásia, Salvador, n. 28, p. 147-178, 2002.

VIDE, Sebastião M. da. Constituições Primeiras do Arcebispado da Bahia. Brasília: Senado Federal, 2007.

WHEAT, David. Atlantic Africa and the Spanish Caribbean, 1570-1640. Chapel Hill: University of North Carolina Press, 2016.

WOLF, Eric; MINTZ, Sidney. An analysis of ritual co-parenthood (compadrazgo). Southwestern Journal of Antropology, v. 6, n. 4, p. 341-368, 1960. 